\title{
An Electrochemical Sensor Based on Bimetallic PtPd Nanoparticles for the Determination of Bisphenol A
}

\author{
Zhiqiang Zhu ${ }^{1, *}$, Xiangyang Miao ${ }^{1}$, Danhong Yan $^{l}$ \\ ${ }^{1}$ Suzhou Chien-shiung Institute of Technology, China \\ *E-mail: zhu29@163.com
}

doi: $10.20964 / 2021.04 .16$

Received: 2 December 2020 / Accepted: 15 January 2021 / Published: 28 February 2021

\begin{abstract}
As a chemical compound with low toxicity, bisphenol A (BPA) mimics oestrogen activity, which can induce precocious puberty. Herein, a sensitive electrochemical sensor is constructed for BPA detection based on flower-like bimetallic PtPd nanoparticles, which are synthesized by a microwave-assisted hydrothermal method. After characterization by transmission electron microscopy (TEM), the electrochemical behaviour of BPA on a PtPd nanoparticle-modified glassy carbon electrode (PtPd/GCE) is studied by electrochemical tests, including cyclic voltammetry $(\mathrm{CV})$, electrochemical impedance spectroscopy (EIS) and differential pulse voltammetry (DPV). Under optimal conditions, the electrochemical response of BPA on PtPd/GCE is linear, with BPA concentrations ranging from 0.75 $\mu \mathrm{M}$ to $600 \mu \mathrm{M}$ and a detection limit of $132 \mathrm{nM}$. Due to the high sensitivity and stability of this sensor, it is used to detect BPA in both food and beverage containers with satisfactory recoveries and acceptable relative standard deviations.
\end{abstract}

Keywords: electrochemistry; bimetallic nanoparticle; bisphenol A

\section{FULL TEXT}

(C) 2021 The Authors. Published by ESG (www.electrochemsci.org). This article is an open access article distributed under the terms and conditions of the Creative Commons Attribution license (http://creativecommons.org/licenses/by/4.0/). 